expression (18). The same conclusion as for the condensation analysis can therefore be drawn with regard to multiple regions in the film.

\section{CONCLUSION}

In the present study the possible existence of multiple superhcatcd and saturated regions in a stagnant binary film, consisting of a vapour and non-condensables, has been examined. The analysis yields the important conclusion that, once fog formation has been detected with the slope condition and a saturated and superheated region determined with the tangency condition, the uniqueness of both regions is assured.
Acknowledgements - The author wishes to thank the management of Akzo Research Laboratories Arnhem for their permission to publish this paper and Messrs. H. P. Korstanje and $G$. Vegt for their support of this work.

\section{REFERENCES}

1. II. J. H. Brouwers, Film models for transport phenomena with fog formation, with application to plastic heat exchangers and condensers, Ph.D. Thesis, Eindhoven University of Technology (1990).

2. H. J. H. Brouwers, Film models for transport phenomena with fog formation : the fog film model, Int. J. Heat Mass Transfer 35, 13-28 (1992).

\title{
The film model applied to free convection over a vertical plate with blowing or suction
}

\section{H. J. H. Brouwers'}

Akzo Research Laboratories Arnhem, Fibers Division, Department of Mechanical Engineering, Velperweg 76, 6824 BM Arnhem, The Netherlands

(Received 27 May 1991 and in final form 19 July 1991)

\section{INTRODUCTION}

FOR MANY years now classical film model correction factors have been successfully used to predict the effect of mass transfer lowards a wall on transport phenomena, such as exerted friction and heat and mass transferred. The correction factors can be derived from a stagnant film analysis and applied to systems using either an imposed (transpiration) mass flux or a diffusional vapour flux (by condensation or evaporation). Recent reviews of the film model are found in Bannwart [1], Bannwart and Bontemps [2], Brouwers and Chesters [3] and Brouwers [4]. Whereas the former two authors extended the model to include the effect of mass transfer on film thickness, the latter investigators added fog formation to the model.

The film model expressions have been applied to forced convective heat flow in the presence of an imposed mass flux by Mickley ot al. [5] and Wang and Tu [6]. Colburn and Drew [7] and Webb and Sardesai [8], among others, fruitfully applied the film model to forced convective diffusional mass transfer. Heat transfer of forced pure vapour flow with wall condensation has been treated with the film model by Mizushina et al. [9]

With respect to free convective flow with mass transfer, the film model has been utilized only by Corradini [10] and Vernier and Solignac [11] in an attempt to model the postulated loss-of-coolant accident in a nuclear reactor. Turbulent free convective flow of wall condensing water vapour in air was considered, but poor agreement was found with the experiments performed. Until now, however, the film model predictions have never been applied to free convective flow problems with imposed wall transpiration. For example, fluid injection is an effective way of cooling and reducing heat transfer to surfaces in extremely hot surroundings.

Hence, in this technical note the classical film model is applied to free convective heat transfer with an imposed mass flux. Subsequently, the predictions are compared with the theoretical results of previous investigators. These results are based on an analysis of the governing equations of laminar

$\dagger$ Present address: Department of Civil Engineering, Twente University, P.O. Box 217, 7500 AE Enschede, The Netherlands. free convective boundary layer flow over a permeable vertical plate with wall transpiration. In this paper the comparison is restricted to laminar free convection because, to the author's knowledge, data on turbulent free convective flow with wall suction or injection are not yet available.

\section{FILM MODEL}

According to film theory the actual local Nusselt number, denoted by $N u_{x}$, in the presence of mass transfer follows from multiplying the zero suction (or neutral) Nusselt number, $N u_{x}^{*}$, by a correction factor

$$
N u_{x}=\Theta_{\mathrm{t} . \mathrm{flim}} N u_{x}^{*} .
$$

The thermal correction factor, commonly referred to as Ackermann correction, follows from Brouwers [4]-among others-as

$$
\Theta_{\mathrm{t}, \mathrm{film}}=\frac{-\phi_{1}}{\mathrm{e}^{-\phi_{1}}-1}
$$

where the dimensionless mass flux towards the wall reads

$$
\phi_{\mathrm{t}}=\frac{\dot{m} c_{\mathrm{p}}}{h_{x}^{*}}=-\frac{v_{\mathrm{w}} \rho c_{\mathrm{p}}}{h_{x}^{*}} .
$$

In this equation $h_{x}^{*}$ represents the local heat transfer coefficient in the case of zero mass transfer. For free convective heat transfer it is defined as

$$
h_{x}^{*}=\frac{N u_{x}^{*} k}{x}
$$

where $x$ is a coordinate along the plate. For free convection over an isothermal impermeable vertical plate by thermal buoyancy the local neutral Nusselt number (see Ostrach [12]) reads

$$
N u_{x}^{*}=\psi(\operatorname{Pr})\left(\frac{G r_{x}}{4}\right)^{1 / 4}
$$

In Table 1 values of $\psi$ are listed for various Prandtl numbers, taken from ref. [12]. In the next section the film model predictions are extensively compared with the results of previous investigators. 


\section{NOMENCLATURE}

\begin{tabular}{|c|c|}
\hline$c_{p}$ & specific heat $\left[\mathrm{J} \mathrm{kg}^{-1} \mathrm{~K}^{-1}\right]$ \\
\hline$E$ & $\begin{array}{l}\text { relative difference between literature and film } \\
\text { model, equation }(8)\end{array}$ \\
\hline$f$ & dimensionless stream function \\
\hline$G r_{x}$ & Grashof number, $g\left(t_{\mathrm{w}}, t_{x}\right) x^{3} / v^{2} T$ \\
\hline$g$ & gravitational acceleration $\left[\mathrm{m} \mathrm{s}^{-2}\right]$ \\
\hline$h_{\mathrm{L}}$ & mean heat transfer coefficient $\left[\mathrm{W} \mathrm{m}^{2} \mathrm{~K} \quad{ }^{1}\right]$ \\
\hline$h_{x}$ & local heat transfer coefficient $\left[\mathrm{W} \mathrm{m} \mathrm{m}^{-2} \mathrm{~K}^{-1}\right]$ \\
\hline$k$ & thermal conductivity $\left[\mathrm{W} \mathrm{m}^{-1} \mathrm{~K}^{-1}\right]$ \\
\hline$L$ & plate length $[\mathrm{m}]$ \\
\hline$\dot{m}$ & mass flux to wall $\left[\mathrm{kg} \mathrm{m}^{-2} \mathrm{~s}^{-1}\right]$ \\
\hline$N u_{x}$ & Nusselt number, $h_{x} x / k$ \\
\hline $\begin{array}{l}n \\
\operatorname{Pr}\end{array}$ & power-law coefnclent \\
\hline$Q$ & dimensionless heat flow \\
\hline$T$ & absolute temperature $[\mathrm{K}]$ \\
\hline$t$ & temperature $[\mathrm{C}]$ \\
\hline$u$ & $\begin{array}{l}\text { component of velocity in the } x \text {-direction } \\
{[\mathrm{ms}} \\
\end{array}$ \\
\hline$l$ & $\begin{array}{l}\text { component of velocity in the } y \text {-direction } \\
{\left[\mathrm{ms} \mathrm{s}^{\prime}\right]}\end{array}$ \\
\hline$x$ & coordinate along the plate $[\mathrm{m}]$ \\
\hline$y$ & coordinate normal to the plate [m]. \\
\hline
\end{tabular}
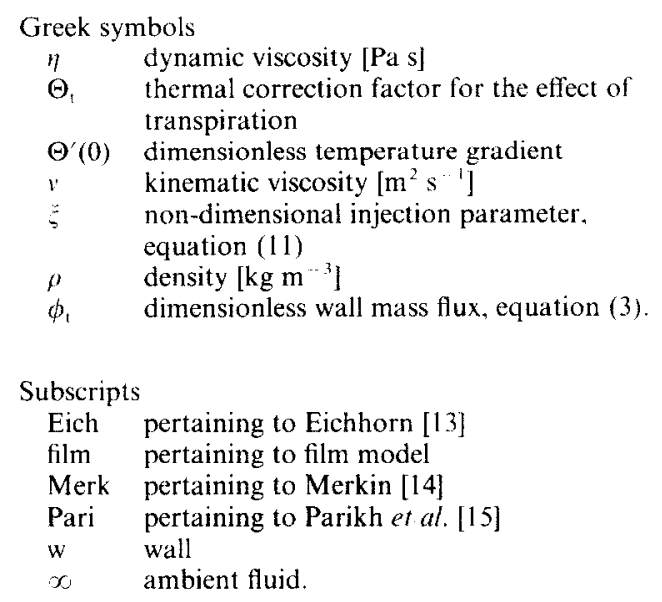

Table I. Values of $\psi$ for various $\operatorname{Pr}$ according to Ostrach [12]

\begin{tabular}{cccccccc}
\hline$P r$ & 0.01 & 0.72 & 0.733 & 1 & 10 & 100 & 1000 \\
\hline$\psi$ & 0.0812 & 0.5046 & 0.5080 & 0.5671 & 1.1694 & 2.191 & 3.966 \\
\hline
\end{tabular}

\section{COMPARISON WITH PREVIOUS WORK}

The film model correction for the effect of mass transfer on heat transfer is compared with the results of Eichhorn [13], Merkin [14] and Parikh et al, [15]. All these foregoing studies concern a laminar free convective boundary layer flow over a vertical plate with imposed transpiration. For the sake of completeness the studies of Sparrow and Cess [16], Mabuchi [17] and Clarke [18] should also be mentioned.

Eichhorn [13] was the first to study the effect of suction and injection on free convective flow. Power-law variations of wall temperature $\left(t_{\mathrm{w}}-t_{x}=C_{1} x^{n}\right)$ and transpiration velocity $\left(v_{\mathrm{w}}=C_{2} \cdot x^{(n-1) \cdot 4}\right)$ were considered under which selfsimilar solutions of the governing equations are possible. For various wall stream function values, $f_{u}$, the dimensionless temperature gradient at the wall, referred to as $-\Theta^{\prime}(0)$, was determined. The Nusselt number ratio now readily follows as

$$
\frac{N u_{x}}{N u_{x}^{*}}=\frac{\Theta^{\prime}(0)}{\Theta^{\prime}(0)^{*}}=\Theta_{\text {t,Eich }},
$$

which can be compared with the film model correction factor. To this end, the dimensionless mass flux $\phi_{\mathrm{t}}$ has to be assessed. This property is related to $f_{w}$ by

$$
\phi_{\mathrm{t}}=-\frac{f_{\mathrm{u}}(n+3) P r}{\Theta^{\prime}(0)^{*}}
$$

(see equations (3) and (4), and equations (11) and (13) from ref. [13]). For $n=0$ and $\operatorname{Pr}=0.73$ values of $\Theta^{\prime}(0)$ were computed by Eichhorn [13] as a function of $f_{\mathrm{w}}$. These values are summarized in Table 2. A glance at this table shows that $-\Theta^{\prime}(0)^{*}$ amounts to 0.507 , which is in agreement with Table $1(\psi(\operatorname{Pr}=0.733)=0.508)$. Table 2 includes both the pertaining film model correction factors and the relative error defined as

$$
E_{\text {Eich }}=\frac{\Theta_{\mathrm{t}, \text {.jim }}-\Theta_{\text {t.Eich }}}{\Theta_{1, \text { Fich }}} .
$$

The tabulated values of $E_{\mathrm{E}}$ indicate that for suction, i.e $f_{w}>0$ and $\phi_{1}>0$, the film model predictions correspond well to the numerical results. For large injection rates, however, the deviation increases; $E_{\text {Eich }}$ then approaches a value of three. The film model deviates less than $5 \%$ from Eichhorn's values for $-0.864 \leqslant \phi_{1} \leqslant 3.320$.

Merkin [14] solved the governing equations of the process considered at constant wall temperature and uniform suction and injection. In this paper asymptotic solutions were also derived for large suction and injection rates.

For various absolute values of the dimensionless transpiration rate $\xi$ the non-dimensional heat transfer was computed and drawn

$$
Q=-\frac{N u_{x} v}{x u_{w}}
$$

Combining equations (3), (4) and (9) yields

$$
\frac{N u_{x}}{N u_{x}^{*}}=\frac{\phi_{t} Q}{P r}=\Theta_{1, \text { Merk }} .
$$

The dimensionless mass flux $\phi_{1}$ is expressed in $\xi$ by considering

$$
\xi=\frac{v_{w} x}{v}\left(\begin{array}{c}
G r_{x} \\
4
\end{array}\right)^{-1.4}
$$

and equations (3) - (5)

$$
\phi_{\uparrow}=-\frac{\zeta P r}{\psi(P r)}
$$

In Fig. I the resulting $\phi_{\mathrm{t}}$ and $\Theta_{\mathrm{t} \text { Merk }}$ are depicted for $\operatorname{Pr}=1$ and $\psi(P r)=0.5671$ (see Table 1). Also in Fig. 1 the film model correction is drawn for $\left|\phi_{\mathrm{t}}\right| \leqslant 3.5$. This figure illustrates the good agreement between the numerical results of Merkin [14] and the basic film model.

Parikh et al. [15] studied both numerically and experimentally the problem of free convection over an isothermal porous vertical plate with uniform transpiration. The 
Table 2. Numerical results of Eichhorn [13] and the film model $(n=0, \operatorname{Pr}=0.73)$

\begin{tabular}{|c|c|c|c|c|c|}
\hline \multicolumn{2}{|c|}{ Eichhorn [13] } & \multirow{2}{*}{$\begin{array}{c}\text { Equation (6) } \\
\Theta_{\text {t.Eich }}\end{array}$} & \multirow{2}{*}{$\begin{array}{c}\text { Equation (7) } \\
\phi_{\mathrm{t}}\end{array}$} & \multirow{2}{*}{$\begin{array}{c}\text { Equation (2) } \\
\Theta_{\text {t.film }}\end{array}$} & \multirow{2}{*}{$\begin{array}{c}\text { Equation }(8) \\
E_{\text {Eich }}(\%)\end{array}$} \\
\hline$f_{\mathrm{w}}$ & $-\Theta^{\prime}(0)$ & & & & \\
\hline-1.0 & 0.00748 & 0.0148 & -4.320 & 0.0582 & 293.2 \\
\hline-0.8 & 0.0264 & 0.0521 & -3.456 & 0.113 & 116.9 \\
\hline-0.6 & 0.0725 & 0.143 & -2.592 & 0.210 & 46.9 \\
\hline-0.4 & 0.162 & 0.320 & -1.728 & 0.373 & 16.6 \\
\hline-0.2 & 0.305 & 0.602 & -0.864 & 0.629 & 4.5 \\
\hline-0.1 & 0.399 & 0.787 & -0.432 & 0.800 & 1.7 \\
\hline 0.0 & 0.507 & 1.000 & 0.000 & 1.000 & 0.0 \\
\hline 0.1 & 0.629 & 1.241 & 0.432 & 1.232 & -0.7 \\
\hline 0.2 & 0.764 & 1.507 & 0.864 & 1.493 & -0.9 \\
\hline 0.3 & 0.912 & 1.799 & 1.296 & 1.784 & -0.8 \\
\hline 0.4 & 1.072 & 2.114 & 1.728 & 2.101 & -0.6 \\
\hline 0.5 & 1.241 & 2.448 & 2.160 & 2.442 & -0.2 \\
\hline 0.6 & 1.420 & 2.801 & 2.592 & 2.802 & -0.04 \\
\hline 0.7 & 1.606 & 3.168 & 3.024 & 3.178 & 0.3 \\
\hline 0.8 & 1.798 & 3.546 & 3.456 & 3.569 & 0.6 \\
\hline 0.9 & 1.994 & 3.933 & 3.888 & 3.969 & 0.9 \\
\hline 1.0 & 2.192 & 4.323 & 4.320 & 4.378 & 1.2 \\
\hline
\end{tabular}

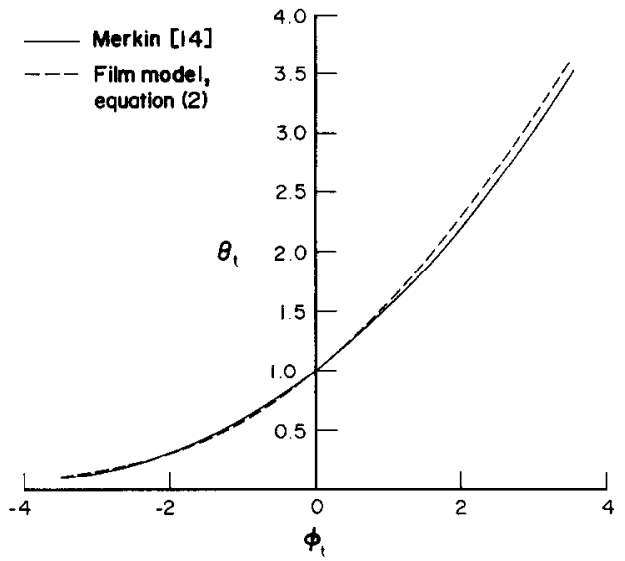

Fig. 1. The effect of transpiration on heat transfer, according to Merkin [14] and the film model.

governing equations were solved for variable physical properties. Their solution, however, differed slightly from Ostrach's [12] constant physical properties solution for air flow along an impermeable plate. Furthermore, both for suction and injection the numerical model closely agreed with experimental data. In their paper, for $P r=0.7$ the ratio of transpiration Nusselt number and neutral Nusselt number (denoted here by $\Theta_{\mathrm{t} \text {.Pari }}$ ) was listed vs $\zeta$ (see equation (11)), and is now included in Table 3 .

The dimensionless mass flux $\phi_{1}$ readily follows from equations (3) $-(5)$ and (11), resulting in equation (12). Following Parikh et al. [15], the value $\psi(\operatorname{Pr}=0.7)$ in equation (12) reads 0.5048 ( $\psi$ is referred to in their paper as ' $\left.-f(0)^{\prime}\right)$. This value of $\psi$ is employed here, though the trend of Table 1 indicates that Ostrach [12] obtained a somewhat smaller value : $\psi(P r=0.72)=0.5046$.

In Table 3 the transformed values of ref. [15] and computed film model corrections are listed. The table illustrates that the two models agree within $5 \%$ for $-2.219 \leqslant \phi_{1} \leqslant$ 2.773 . Note that the relative difference between both models, governed by $E_{\mathrm{Pari}}$, shows the same trend as the lines depicted in Fig. 1. For very negative $\phi_{\mathrm{t}}$ the film model overpredicts heat transfer, for moderate negative $\phi_{\mathrm{t}}$ it underestimates heat transfer rates, while for positive $\phi_{1}$ these rates are overestimated again.
Table 3. Numerical results of Parikh et al. [15] and the film model $(\operatorname{Pr}=0.7)$

\begin{tabular}{|c|c|c|c|c|}
\hline \multicolumn{2}{|c|}{$\begin{array}{c}\text { Parikh } \\
\text { et al. }[15]\end{array}$} & \multirow{2}{*}{$\begin{array}{c}\text { Equation (12) } \\
\phi_{\mathrm{t}}\end{array}$} & \multirow{2}{*}{$\begin{array}{c}\text { Equation (2) } \\
\Theta_{\mathbf{t} \text {.film }}\end{array}$} & \multirow{2}{*}{$\begin{array}{c}\text { Equation (8) } \\
E_{\text {Pari }}(\%)\end{array}$} \\
\hline$\check{\xi}$ & $\Theta_{\mathrm{t}, \text { Pari }}$ & & & \\
\hline 2.4 & 0.085 & -3.328 & 0.124 & 45.9 \\
\hline 2.0 & 0.160 & -2.773 & 0.185 & 15.6 \\
\hline 1.6 & 0.260 & -2.219 & 0.271 & 4.2 \\
\hline 1.2 & 0.380 & -1.664 & 0.389 & 2.4 \\
\hline 1.0 & 0.465 & -1.387 & 0.462 & -0.6 \\
\hline 0.8 & 0.550 & -1.109 & 0.546 & -0.7 \\
\hline 0.4 & 0.755 & -0.555 & 0.748 & -0.9 \\
\hline 0.0 & 1.000 & 0.000 & 1.000 & 0.0 \\
\hline-0.4 & 1.300 & 0.555 & 1.303 & 0.2 \\
\hline-0.8 & 1.625 & 1.109 & 1.655 & 1.8 \\
\hline-1.0 & 1.805 & 1.387 & 1.849 & 2.4 \\
\hline-1.2 & 1.990 & 1.664 & 2.053 & 3.2 \\
\hline-1.6 & 2.395 & 2.219 & 2.490 & 4.0 \\
\hline-2.0 & 2.820 & 2.773 & 2.958 & 4.9 \\
\hline-2.4 & 3.245 & 3.328 & 3.452 & 6.4 \\
\hline
\end{tabular}

In the foregoing the attention has been focused on the effect of mass transfer on local heat transfer coefficients. In the following the effect on mean heat transfer coefficients is analysed in some detail.

The mean heat transfer coefficient is defined as

$$
h_{\mathrm{L}}=\psi(P r) \frac{k}{L} \int_{x=0}^{L} \frac{1}{x}\left(\frac{G r_{x}}{4}\right)^{1 / 4} \Theta_{\mathrm{L} \text {. firm }} \mathrm{d} x
$$

(see equations (1), (4) and (5)). For free convection with mass transfer, i.e. $\Theta_{1 . f i m} \neq 1$, this integral, generally speaking, cannot be solved in closed form, since $\phi_{\text {t.film }}$ depends on $x$. Eichhorn's [13] power-law variation of the transpiration velocity $\left(v_{\mathrm{w}}=C_{2} x^{-1 / 4}\right)$, however, permits an analytic treatment of the integral. In this case $\phi_{t . f i m}$, and consequently $\Theta_{\text {i.film }}$, are constant (see equations (2)-(5)). Equation (13) then becomes

$$
h_{\mathrm{L}}=\psi(\operatorname{Pr}) \frac{4 k}{3 L}\left(\frac{G r_{\mathrm{L}}}{4}\right)^{1 / 4} \Theta_{\mathrm{L}, \mathrm{film}} .
$$

Hence, in this special case the mean heat transfer coefficient simply follows from multiplying the mean neutral heat transfer coefficient (which is usually documented in the literature) 
by the constant film model correction factor. Again it must be stressed for all other problems, e.g. uniform transpiration. that equation (13) has to be evaluated numerically.

\section{CONCLUSIONS}

In this note the film model has been applied to free convective heat transfer in the presence ol mass transfer. The film model correction factor for heat transfer has been extensively compared with existing theoretical results of previous investigators. These elaborations concerned a laminar free convective boundary layer flow over an isothermal porous vertical plate. In these studies the governing equations were derived and solved numerically, the Prandtl number ranging from 0.7 to 1

For uniform wall transpiration, the film model agreed with the literature within $5 \%$ for $-2.219 \leqslant \phi_{t} \leqslant 2.773$. The film model correction appeared to correlate with the same accuracy for a power-law distribution of the transpiration velocity and $-0.864 \leqslant \phi_{\mathrm{t}} \leqslant 4.320$. For the said cases and ranges of $\phi_{1}$ the basic film model is well suited to describe the effect of mass transfer on free convective sensible heat transfer. Furthermore, these ranges of $\phi_{i}$ extend well beyond a large number of current practical applications.

In this note the classical fim model for friction has not yet been applied to the examined physical process. For the studies referred to revealed that the exerted friction is reduced by both injection and large suction. The film model correction for friction, however, predicts enhanced and reduced friction for suction and injection, respectively (likewise heat transfer). This can be attributed to the momentum equation of the film model from which the correction factor is derived. In this equation the buoyancy and pressure gradient terms are omitted [1 4]. Though this neglect is allowed for forced convective flow, it is unacceptable for free convection. This insight may form a challenge to derive a friction correction factor from a film model with retained buoyancy and pressure gradient terms, and to apply this factor to free convective flow with transpiration.

Acknowledgements - The author wishes to thank the management of Akzo Research Laboratories Arnhem for their permission to publish this paper and Messrs. H. P. Korstanje and $G$. Vegt for their support of this work.

\section{REFERENCES}

1. A. C. Bannwart, Etude théoretique et experimentale de la condensation d'une vapeur en presence d'incondensables. Thèse de Doctorat, Institut National Polytechnique de Grenoble (1988) [in French].

2. A. C. Bannwart and A. Bontemps. Condensation of a vapour with incondensables: an improved gas phase film model accounting for the effect of mass transfer on film thicknesses, Int. J. Heat Mass Transfer 33, 1465-1474 (1990).

3. H. J. H. Brouwers and A. K. Chesters, Film models for transport phenomena with fog formation: the classical film model, Int. J. Heat Mass Transfer 35, 1-11 (1992).

4. H. J. H. Brouwers, Film models for transport phenomena with fog formation, with application to plastic heal exchangers and condensers, Ph.D. Thesis, Eindhoven University of Technology (1990)

5. H. S. Mickley, R. C. Ross, A. L. Squyers and W. F. Stewart, Heat, mass, and momentum iransfer for flow over a flat plate with blowing or suction, NACA Technical Note 3208 (1954).

6. C. Y. Wang and C. J. Tu, Effects of non-condensable gas on laminar film condensation in a vertical tube, Int. J. Heat Mass Transfer 31, 23392345 (1988).

7. A. P. Colburn and T. B. Drew. The condensation of mixed vapours, Trans. A.I.Ch.E. 33, 197212 (1937).

8. D. R. Webb and R. G. Sardesai, Verification of multicomponent mass transfer models for condensation inside a vertical tube, $I n t . J$. Multiphase Flow 7,507-520 (1981).

9. T. Mizushina. R. Ito, S. Yamashita and H. Kamimura, Film condensation of a pute superheated vapor inside a vertical tube, Int. Chem. Engng 18,672 679 (1978)

10. M. L. Corradini, Turbulent condensation on a cold wall in the presence of a noncondensable gas, Nuclear Technol. 64, 186 195 (1984).

11. P. J. Vernier and P. Solignac, A test of some condensation models in the presence of a noncondensable gas against the Ecotra experiment. Nuclear Technology 77,8291 (1987).

12. S. Ostrach. An analysis of laminar free convection flow and heat transfer about a flat plate parallel to the direction of the generating body force. NACA Technical Note 2635 (1952) or NACA Report 1111 (1953).

13. R. Eichhorn. The effects of mass transfer on free convection flow, $J$. Heat Transfer 82, 260263 (1960).

14. I. H. Merkin, Free convection with blowing and suction, Int, J. Heat Mass Transfer 15,989 999 (1972).

15. P. G. Parikh, R. J. Moffat, W. M. Kays and D. Bershader, Free convection over a vertical porous plate with transpiration, Int If Heat Moss Tronster 17, 1465.1474 (1974).

16. E. M. Sparrow and R. D. Cess, Free convection with blowing or suction, J. Heat Transfer 83, 387 389 (1961).

17. 1. Mabuchi. The effect of blowing or suction on heat transfer by free convection from a vertical flat plate, Bull. J.S.M.E. 6, 223-230 (1963).

18. J. F. Clarke, Transpiration and natural convection: the vertical plate problem, $J$, Fluid Mech. 57(1), 45-61 (1973).

\title{
Transient combined conduction and radiation in an absorbing emitting and anisotropically-scattering medium with variable thermal conductivity
}

\author{
Chung-Jen Tseng and Hsin-Sen Chu
}

Department of Mechanical Engineering, National Chiao Tung University, Hsinchu, Taiwan 30050, China

(Received 13 January 1991 and in final form 22 May 1991)

\section{INTRODUCTION}

THE ANALYSIS of steady [1 -6] or unsteady [7-10] simultaneous radiation and conduction in an absorbing, emitting and scat tering medium has received extensive attention in recent years due to its wide applications in engineering. While most previous works considered constant thermal conductivity, it is well known that the thermal conductivities of most nonmetal materials are not constant when subjected to moderate, say $100 \mathrm{~K}$, or large temperature differences. Instead, the thermal conductivity of most nonmetal materials displays a linear relationship with temperature and can play a significant role on overall heat transfer. In a recent study, Chu and Tseng [11] investigated the effect of variable thermal 